\title{
Randomized Controlled Comparison of Two Cognitive Behavioral Therapies for Obese Children: Mother versus Mother-Child Cognitive Behavioral Therapy
}

\author{
Simone Munsch ${ }^{\mathrm{a}}$ Binia Roth ${ }^{\mathrm{b}}$ Tanja Michael ${ }^{\mathrm{a}} \quad$ Andrea Hans Meyer $^{\mathrm{a}}$ \\ Esther Biedert ${ }^{\mathrm{a}}$ Sandra Roth ${ }^{\mathrm{a}}$ Vanessa Speck $^{\mathrm{a}} \quad$ Urs Zumsteg $^{\mathrm{c}}$ Emanuel Isler $^{\mathrm{b}}$ \\ Jürgen Margrafa \\ ${ }^{a}$ Faculty of Psychology, Clinical Psychology and Psychotherapy, University of Basel, Basel, ${ }^{\mathrm{b}}$ Child and Adolescent \\ Psychiatric Service of Basel-Land, Kantonsspital Bruderholz, Bruderholz, and 'University Children's Hospital, POB, \\ Basel, Switzerland
}

\section{Key Words}

Childhood obesity $\cdot$ Parent involvement $\cdot$ Cognitive

behavioral treatment $\cdot$ Randomized controlled trial

\begin{abstract}
Background: Parent-child treatments have been shown to be superior to child-focused treatments of childhood obesity. Yet until now, the comparative effectiveness of parentonly and parent-child approaches has been little studied. Method: Fifty-six obese children and their families were randomly assigned to a 16-session cognitive behavioral therapy (CBT) for the parents only or for a combined treatment of parents and children. Children's percent overweight, the body mass index of their mothers, and behavioral and psychological problems of children and mothers were assessed. Results: Both treatments reduced children's percent overweight significantly and equally by 6-month follow-up. Also both treatments provided similar results in reducing general behavior problems (externalizing and internalizing behavior problems), global and social anxiety, and depression. Conclusions: Our results point to a comparable efficacy of the two treatments. Further, psychological well-being of both
\end{abstract}

mothers and children can be improved in a CBT for obese children and their parents. Future studies should focus on finding ways to improve the adherence of families to longterm treatment of obesity in childhood.

Copyright $\odot 2008$ S. Karger AG, Basel

The prevalence of overweight and obesity among children aged 6-11 years has more than tripled in the United States in recent years, rising from $4 \%$ in 1971-1974 (National Health and Nutrition Examination Survey) to 16\% in 1999-2002 [1]. Childhood obesity is also becoming more common in Western Europe [2-5]. Besides the various health consequences of childhood obesity [6], many obese children suffer from behavioral problems or mental disorders [7-15].

Nowadays, biological, psychological, and psychosocial factors are associated with the development and maintenance of obesity [16-19]. In children, the model behavior of the family plays an important role in the development of obesity [20-24]. Clinical research in childhood obesity has reported short- and long-term superiority of parent involvement in treatment compared to the treatment of

\section{KARGER}

Fax +41613061234 E-Mail karger@karger.ch www.karger.com
(C) 2008 S. Karger AG, Basel

$0033-3190 / 08 / 0774-0235 \$ 24.50 / 0$

Accessible online at:

www.karger.com/pps
Simone Munsch, $\mathrm{PhD}$

Faculty of Psychology, University of Basel

Missionsstrasse 60/62a

$\mathrm{CH}-4055$ Basel (Switzerland)

Tel. +41 6126706 57, Fax +416126706 48, E-Mail simone.munsch@unibas.ch 
the child alone [25-30]. It is suggested that parents should be the main agents of change [31-33]; but to conclude that the exclusive treatment of parents is the treatment of choice would be premature, as there is limited data on the comparative effectiveness of parent-exclusive and parentchild approaches (the latter being where parents and children are treated simultaneously but separately) [33].

In the current study, we investigated whether the treatment of parents only would be as efficacious as a parentchild treatment in a randomized controlled clinical trial. Our group treatment approach, TAKE [Training adipöser Kinder und deren Eltern ('training of obese children and their parents')], targeted weight stabilization and reduction of behavioral problems of obese children aged 8-12 years [34-36]. We further sought to expand on prior research and investigated psychological variables during the treatment course using valid instruments and accounted for methodological considerations by providing detailed information about treatment content, therapists, compliance, ratings of suitability and treatment integrity.

\section{Method}

\section{Participants}

The study was conducted at the Department of Clinical Psychology and Psychotherapy of the University of Basel and at the Children's and Adolescents' Psychiatry Outpatient Clinic in Bruderholz (Switzerland). Study inclusion criteria required children to be between 8 and 12 years old with a body mass index (BMI) above the 85th percentile adjusted for gender and age.

Participating family members were able to speak and write in German. Parents and children meeting the criteria of the DSMIV-TR [37] for mental disorders warranting immediate treatment (assessed in a clinical interview), such as suicidal tendency, psychosis, mania, organic dementia, or substance abuse disorder, were excluded from the study. All participants were free from diabetes, heart disease, and endocrine disorders. Further exclusion criteria were parents' or children's participation in a diet program or other psychotherapy treatment with weight loss medication. As there were only 4 fathers eligible for treatment, we excluded fathers' data from the analyses. For a diagram of the participant flow see figure 1 .

The Swiss National Foundation funded the study for a period of about 2 years. Although we made extensive recruitment efforts through different media, recruitment turned out to be difficult and we did not reach the necessary sample size of 68 families with obese children within the given time span (the target sample size of 68 was based on a repeated-measures analysis with $\alpha=0.05$, $1-\beta=0.8$, and a medium effect size for the linear term of the interaction between treatment and time, assuming a dropout rate of $20 \%$ [38]; note that all subjects who dropped out of the study would be completely eliminated from the analysis. At the time of the analysis of the data we therefore decided to use linear mixed models; see below).
The local Ethics Committee Board of Basel approved the protocol. Families signed up for a study entitled 'Treatment for obese children and their parents' and gave written informed consent at the initial Institute visit.

\section{Study Design}

After screening, families were randomly assigned according to a permuted block design to either the mother-child (condition A) or the mother-only (condition B) cognitive behavioral therapy (CBT) treatment [39] (fig. 1). In both conditions, mothers received $\mathrm{CBT}$. Children in condition B attended a relaxation training (progressive muscle relaxation training, PMR) of equal frequency and duration to the disorder-specific CBT of children in condition A. This procedure was chosen because PMR was shown to account for possible nonspecific effects of 'attention' [40-43]. For practical and ethical reasons, we were not able to run an additional control group, such as a waiting list group. Each treatment group started whenever 6-8 families had been recruited. This recruitment scheme resulted in a slight imbalance in sample size between the two treatment conditions (fig. 1).

\section{Treatment}

TAKE Protocol

The TAKE program was developed according to the guidelines of Barlow and Dietz [44] and Summerbell et al. [45] by Simone Munsch and Binia Roth (manual in preparation). Treatment was tailored to the specific problems in the individual mother-child dyad according to the individual-treatment-in-group approach [46].

The group sessions began with a short overview of the topic, then individual difficulties and progress with homework were discussed and the group established coping strategies. Afterwards the major topics of the sessions were implemented and new homework was assigned. Interventions throughout the program were highly interactive, proceeded step by step, and involved the group as a whole as well as individual mothers and children.

During the first 3 sessions, families were informed about the treatment protocol and about the model of etiology and maintenance of obesity in childhood. In the next 2 sessions, the basic rules of regular and balanced nutrition were introduced using the stoplight diet, which categorizes foods as low, medium, or high fat and instructs users to eat freely from the low-fat category, cautiously from the middle category, and only rarely from the highfat foods [47]. To implement a functional eating style, mothers were encouraged to follow three basic food rules for family meals: (1) 'any food on the table may be eaten by all family members'; (2) 'offer only restricted amounts of high-fat foods', and (3) 'offer a sufficient amount of low-fat food so that the child can eat until satiated'. Sessions 4, 5 and 6 aimed at encouraging mothers to model physical activity in daily family life. Goal achievement was self-monitored daily by the children and mothers and rewarded regularly according to an individualized plan ('principle of token economies' [48]) for each mother-child dyad. In session 8, maintenance of achieved behavior change and issues of motivation were addressed. Sessions 7 and 9 focused on enabling mothers to cope with the social stigmatization of obesity for their offspring. In session 10 as well as during the 6 monthly aftercare sessions, goal achievement and relapse prevention skills were implemented. For further details about the goals and techniques of the treatment protocols of conditions $\mathrm{A}$ and $\mathrm{B}$, see table 1 . 


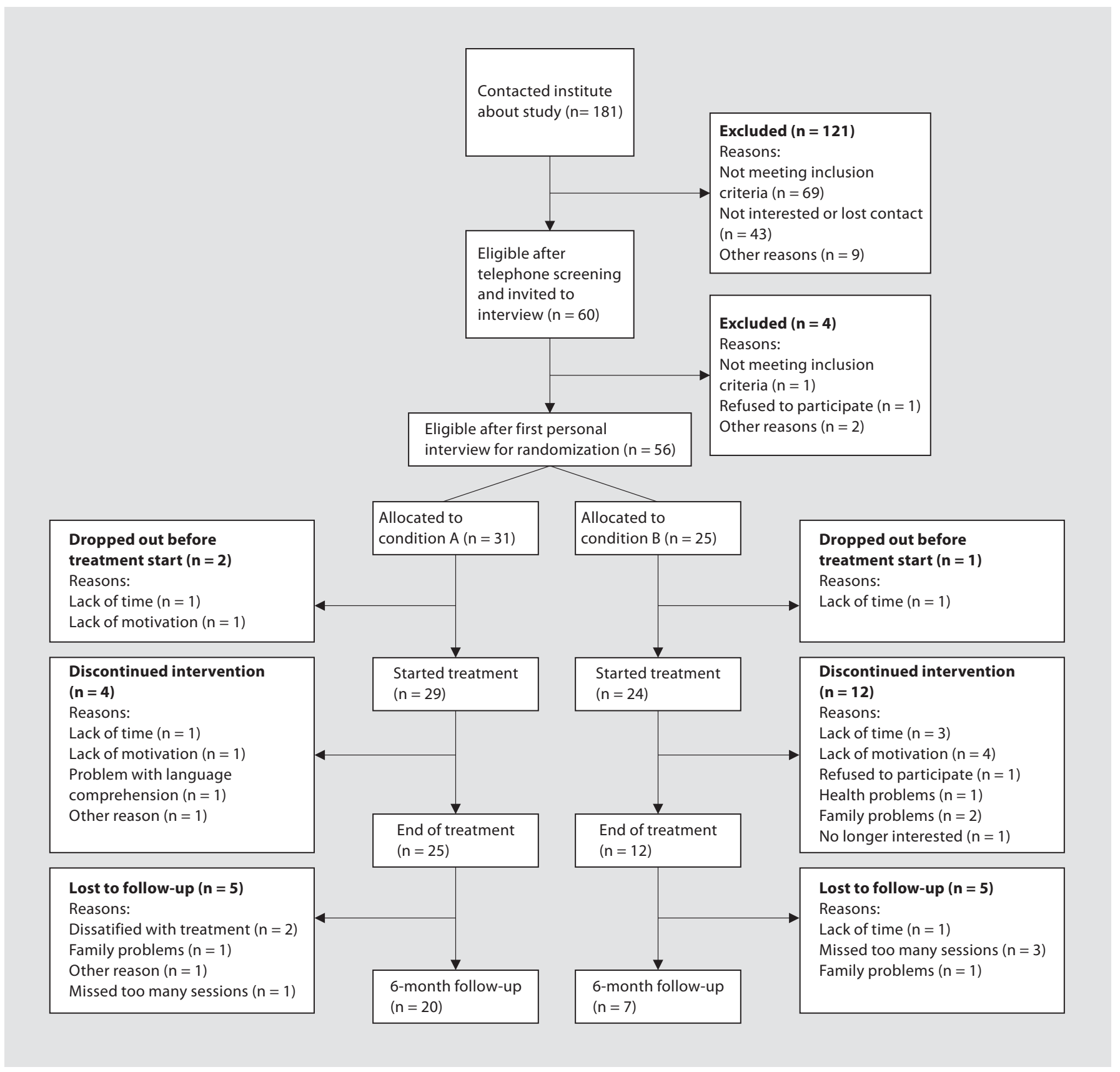

Fig. 1. Participant flow. Condition A: mother-child treatment. Condition B: mother-only treatment.

PMR for Children

The nonspecific control condition for the children in the specialized CBT for mothers only was a PMR treatment for children, following Speck's [49] manual, in which overweight or obesity and the management of these conditions were not targeted. The treatment took place in separate but parallel groups with up to 6 children and 6-12 mothers in each group. The treatment phase consisted of 10 weekly 120 -min sessions and 6 monthly sessions.
Both parent-child (condition A) and mother-only (condition B) groups were led by 6 psychotherapists with clinical experience of at least 2 years of specialized CBT education and by a cotherapist, following a standardized treatment protocol. Cotherapists were master's degree students of the University of Basel, Department of Clinical Psychology and Psychotherapy. All therapists were trained and supervised weekly by one of the authors (S.M. or B.R.). 
Table 1. Details about the goals and techniques of the treatment protocols of conditions A and B

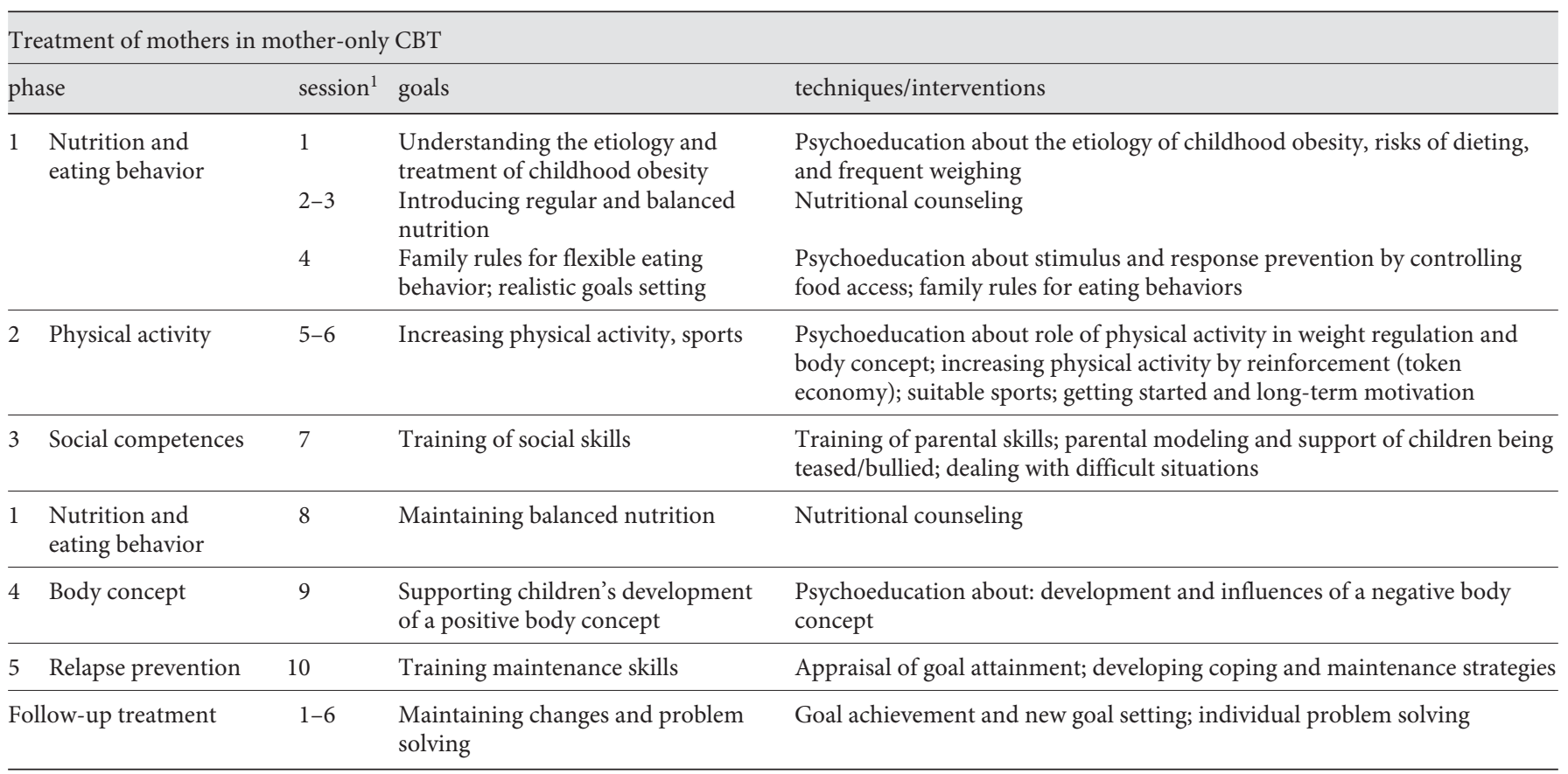

\begin{tabular}{|c|c|c|c|c|c|c|}
\hline \multicolumn{4}{|c|}{ Treatment of children in mother-child CBT (condition A) } & \multicolumn{3}{|c|}{ Children's PMR (condition B) ${ }^{2}$} \\
\hline phase & $\operatorname{session}^{1}$ & goals & techniques/interventions & $\begin{array}{l}\text { ses- } \\
\operatorname{sion}^{1}\end{array}$ & goals & $\begin{array}{l}\text { techniques/ } \\
\text { interventions }\end{array}$ \\
\hline \multirow[t]{3}{*}{$\begin{array}{l}\text { Nutrition and eating } \\
\text { behavior }\end{array}$} & 1 & $\begin{array}{l}\text { Understanding the etiology } \\
\text { and treatment of obesity }\end{array}$ & $\begin{array}{l}\text { Psychoeducation about } \\
\text { the etiology of childhood obesity, risks of dieting, } \\
\text { introducing weekly weighing }\end{array}$ & & & \\
\hline & 2 & $\begin{array}{l}\text { Basic nutritional education } \\
\text { (by psychologist) }\end{array}$ & $\begin{array}{l}\text { Regular eating behavior classifying nutrients by } \\
\text { the stoplight diet }\end{array}$ & & & \\
\hline & 3 & Reinforcement and tokens & Token plan/contract for regular and healthy eating & & & \\
\hline 2 Physical activity & $4-5$ & $\begin{array}{l}\text { Increasing physical } \\
\text { activity, sports }\end{array}$ & $\begin{array}{l}\text { Embedding physical activity in everyday life; } \\
\text { increasing motivation; reinforcement plan } \\
\text { (token economy) for increased physical activity; } \\
\text { weekly 1-hour sport sessions (by gym instructor) }\end{array}$ & $1-10$ & $\begin{array}{l}\text { Handling } \\
\text { stress }\end{array}$ & $\begin{array}{l}\text { PMR: } \\
\text { exercises }\end{array}$ \\
\hline
\end{tabular}

Lessons in physical activity (phases 3-5)

3 Social competences $\quad 6-7 \quad$ Training in

self-assertiveness

Self-assertiveness training with focus on social

skills and saying 'no' to food offers

$8 \quad$ Training in

Telling teasers off! Development of an antibullying

self-assertiveness plan, role modeling

\begin{tabular}{lllll}
\hline 4 Body concept & 9 & $\begin{array}{l}\text { Developing a positive } \\
\text { body concept }\end{array}$ & $\begin{array}{l}\text { Identifying and reinforcing positive qualities of } \\
\text { one's own body and person }\end{array}$ \\
\hline 5 & Relapse prevention & 10 & Training maintenance skills & Developing and exercising maintenance strategies \\
\hline Follow-up treatment & $1-6$ & $\begin{array}{l}\text { Maintaining changes } \\
\text { and problem solving }\end{array}$ & $\begin{array}{l}\text { Goal achievement and new goal setting; } \\
\text { individual problem solving }\end{array} \quad \begin{array}{l}\text { Handling PMR: } \\
\text { stress }\end{array}$ \\
\hline
\end{tabular}

${ }^{1}$ Phases 1-5: sessions were weekly; follow-up: sessions were monthly.

${ }^{2}$ Nonspecific treatment condition for children in the specialized CBT for mothers only. 


\section{Assessments}

Children's sociodemographics and mental disorders were assessed at baseline. Children's percent overweight, depression [Depressionsinventar für Kinder und Jugendliche [50] (DIKJ)], measures of anxiety [State-Trait Anxiety Inventory for Children [51] and its German [52] version State und Trait Angst-Inventar für Kinder (STAIK); Social Anxiety Scale for Children-Revised (SASC-R) [53] and its German [54] version; subscales: Fear of Negative Evaluation (FNE), Social Avoidance and Distress with Peers (SAD)], and behavior problems [Child Behavior Checklist (CBCL) [55] and its German [56] version] were all assessed at the beginning and end of treatment and at the end of the 6-month follow-up.

Socioeconomic status (SES) and mental disorders in mothers were also assessed at baseline. Mothers' BMI, eating behavior [Eating Disorder Examination (EDE) [57] and its German [58] version], depressive feelings [Beck Depression Inventory (BDI) [59] and its German [60] version], anxiety measures [Beck Anxiety Inventory (BAI) [61] and its German [62] version], life satisfaction [Fragebogen zur Lebenszufriedenheit [63] (FLZ)] and ratings of self-efficacy were all assessed at the beginning and end of treatment and at the end of the 6-month follow-up.

The questionnaires possess good psychometric properties such as internal consistency, reliability, and convergent validity and were mailed to the families 1 week prior to the start of treatment. The children and their mothers were requested to bring the completed set of questionnaires to the first session. The questionnaires took on average about $1 \mathrm{~h}$ to complete. The interviews of mothers and children were held separately, in 1 session, over $1-2 \mathrm{~h}$.

\section{BMI and Percent Overweight}

Children were weighed in underwear, mothers in light clothes to the nearest $0.1 \mathrm{~kg}$ on a Seca electronic balance (Seca, Vogel + Halke, Germany) and height was measured without shoes to the nearest $0.1 \mathrm{~cm}$ with a stadiometer. BMI was calculated as weight in kilograms divided by the square of height in meters. After children were weighed and measured, the weighted BMI [percent overweight $=($ effective BMI/BMI 50th percentile $)-1]$ was calculated based on age and gender [64].

\section{Mental Disorders and Eating Disorder Pathology}

\section{Children}

To assess current and lifetime mental disorders in children, the structured interview for mental disorders in childhood, Diagnostisches Interview bei psychischen Störungen im Kindes- und Jugendalter (K-DIPS) [65], was administered in child and parent versions. Standardized administration of the interviews was ensured by weekly supervision by two of the authors (S.M. and B.R.). Binge eating symptomatology was assessed in a screening interview, following Marcus and Kalarchian [11]. A German version was developed specifically for this study and is available from the authors.

Children's behavioral problems and competences were further assessed with the German version of the CBCL [56], a 138-item questionnaire completed by the parents. This instrument provides a standardized description of skills and emotional and behavioral problems in 4- to 18 -year-old children. The first part results in 3 subscales (activities, social competences, and school competences) and a total competence score. The second part yields 8 scales of behavior problems (withdrawal, somatic complaints, anxiety/depression, social problems, thought problems, attention problems, delinquent behavior, aggressive behavior) that are subsumed in the 2 subscales of internalizing and externalizing behavior problems, and in a total problem score.

\section{Mothers}

We used the German version of the EDE [58] to assess disordered eating behavior such as eating concern, shape concern, weight concern, and dietary restraint. A semi-structured interview to assess current and lifetime mental disorders [Diagnostisches Kurzinterview bei psychischen Störungen [66] (Mini-DIPS), screening for mental disorders] was administered by specifically trained and supervised interviewers.

\section{Depression and Anxiety Ratings}

Children

All children completed questionnaires to assess depressive symptoms (Children's Depression Inventory [67]; DIKJ [50]), anxiety (STAIK [52]; SASC-R [53] and its German version [54]), $\mathrm{SAD}$, and FNE.

\section{Mothers}

Individuals completed the German versions of the BDI [60] and the BAI [62] to measure depression and anxiety.

Socioeconomic Status

SES was assessed by a questionnaire especially developed for the study (available from the authors). According to their occupations, families were categorized into a low (e.g. unemployed, homemaker, factory worker), medium (e.g. foreman/forewoman, master craftsman/craftswoman, self-employed in trade/industry) or high (e.g. manager, senior official) SES group.

\section{Integrity of Treatment}

Two independent raters (students of clinical psychology holding a bachelor's degree) separately judged adherence to treatment protocol. Eight randomly selected videotaped sessions of conditions A and B were coded with a session-dependent 25- to 34-item (child sessions) or a 15- to 18-item (parent sessions) questionnaire especially developed for the study (unpublished data, available from the authors). Neither rater acted as a therapist or cotherapist in the treatment trial. Raters were blinded to which session and which therapy condition they were rating. The rating included treatment-specific questions such as 'Was the importance of regular eating behavior explained comprehensibly?' and 'Were the interventions tailored to the specific familial setting?' for the CBT of the mothers in either condition A or B and 'Was the effect of PMR discussed with all participants?' for the children of the mothers in condition B.

\section{Suitability of Treatment}

Suitability ratings of treatment of mothers were assessed with an item from the session protocol of Grawe et al. [68] (item 19: 'I think another therapeutic procedure would be more suitable for me') that was administered on a 7-point Likert scale from -3 ('not at all') to +3 ('yes, exactly'). Ratings were assessed in the middle and at the end of the series of weekly treatments and at the 6month follow-up. 
Table 2. Sample characteristics of children

\begin{tabular}{|c|c|c|c|c|c|}
\hline & \multicolumn{4}{|l|}{ Study group } & \multirow{2}{*}{$\begin{array}{l}\text { Test statistic and } \\
\text { significance }\end{array}$} \\
\hline & \multicolumn{2}{|c|}{ mother-child CBT } & \multicolumn{2}{|c|}{ CBT for mothers only } & \\
\hline \multirow{8}{*}{$\begin{array}{l}\text { Female } \\
\text { Male } \\
\text { Age (mean } \pm \text { SD), years } \\
\text { Percent overweight (mean } \pm \text { SD) } \\
\text { BMI (mean } \pm \text { SD) } \\
\text { Age of onset of obesity (mean } \pm \text { SD), years } \\
\text { BED diagnosis }{ }^{\mathrm{a}} \\
\text { Mental disorders }^{\mathrm{b}}\end{array}$} & \multicolumn{2}{|l|}{$17(58.6)$} & \multicolumn{2}{|l|}{$15(62.5)$} & \multirow[t]{2}{*}{$\chi^{2}=0.83 ; p=0.77$} \\
\hline & \multicolumn{2}{|l|}{$12(41.4)$} & & \\
\hline & $10.3 \pm 1.4$ & $\mathrm{n}=28$ & $10.6 \pm 1.5$ & $\begin{array}{c}9(37.5) \\
10.6+15\end{array}$ & $\mathrm{t}_{41}=-0.59 ; \mathrm{p}=0.56$ \\
\hline & $55.4 \pm 17.9$ & $\mathrm{n}=28$ & $62.4 \pm 27.2$ & $\mathrm{n}=21$ & $\mathrm{t}_{33}=-1.03 ; \mathrm{p}=0.31$ \\
\hline & $26.5 \pm 3.3$ & $\mathrm{n}=28$ & $28.0 \pm 5.4$ & $\mathrm{n}=21$ & $\mathrm{t}_{31}=-1.15 ; \mathrm{p}=0.26$ \\
\hline & $5.2 \pm 2.4$ & $\mathrm{n}=27$ & $5.1 \pm 3.0$ & $\mathrm{n}=23$ & $\mathrm{t}_{42}=0.78 ; \mathrm{p}=0.94$ \\
\hline & $6(20.7)$ & $\mathrm{n}=26$ & $9(37.5)$ & $\mathrm{n}=23$ & $\chi^{2}=1.48 ; \mathrm{p}=0.22$ \\
\hline & \multicolumn{2}{|l|}{$10^{c}(34.5)$} & \multicolumn{2}{|l|}{$8^{\mathrm{d}}(33.3)$} & $\chi^{2}=0.01 ; p=0.93$ \\
\hline
\end{tabular}

$\mathrm{BED}=$ Binge eating disorder. Figures in parentheses indicate percentages

${ }^{a}$ Diagnosis criteria by Marcus and Kalarchian [11]. ${ }^{\mathrm{b}}$ Kinder-DIPS [65]. ${ }^{\mathrm{c}}$ Attention deficit hyperactivity disorders $(\mathrm{n}=4)$, social phobias $(n=3)$, oppositional defiant disorders $(n=2)$, obsessive-compulsive disorder $(n=1) .{ }^{d}$ Attention deficit hyperactivity disorders $(n=2)$, oppositional defiant disorders $(n=2)$, major depression $(n=1)$, dysthymia $(n=1)$, social phobia $(n=1)$, specific phobia $(\mathrm{n}=1)$.

\section{Statistical Analysis}

To compare sample characteristics between treatments we used $t$ tests for independent samples for continuously distributed variables and $\chi^{2}$ tests for categorical variables. Differences between the two treatments in suitability of treatment, compliance, and treatment integrity were all tested using t tests for independent samples. To measure treatment integrity we calculated the gamma coefficient. Differences in dropout rates between the two treatments were tested using the $\chi^{2}$ test.

The primary outcome variables were percent overweight for children and BMI for mothers. Secondary outcomes included measures of behavior problems (CBCL scores), anxiety, and depression in children, and eating behavior (EDE global score), anxiety, and depression in mothers.

To compare the two treatment modalities from baseline to 6 month follow-up we used linear mixed models. In studies where missing values frequently occur and if the absence only depends on observed and not on unobserved measurements (a so-called missing-at-random pattern [69]), linear mixed models have been shown to lead to more precise and less biased results compared with complete case analyses or analyses in which missing values have been imputed prior to the analysis using the last-observation-carried-forward (LOCF) method. Also, results based on the LOCF method can be biased in either direction and thus can be interpreted as being conservative or liberal [70]. In linear mixed models, participants with missing data are not omitted from the analysis, in contrast to the split-plot repeated-measures approach that requires complete cases for each time point and participant. Our model allowed us to test for the effect of temporal changes averaged across the two treatments, for the difference between the two treatments averaged across all assessment points, and, most importantly, for temporal changes between the two treatments (time $\times$ treatment interaction).

The factor time consists of a linear and a quadratic component. The linear component tests for a positive or negative linear trend over time, whereas the quadratic component tests for a cur- vilinear trend over time, such as a temporal decline followed by no changes or an increase. Note that in the presence of a quadratic component the linear component is not constant but represents the instantaneous rate of change at a particular time point (here: end of treatment). This is particularly important if the quadratic component is high, pointing to a time trajectory that strongly deviates from linearity. When reporting results, we will concentrate on the two main contrasts 'linear time trend' and 'quadratic time trend' and on the two interactions 'linear time trend $\times$ treatment' and 'quadratic time trend $\times$ treatment'.

The number of assessment points varies across the different outcomes. The linear mixed model we used allowed the intercepts and slopes to vary randomly among the individuals, leading to an implicit covariance structure. Parameter estimates were obtained using the restricted maximum likelihood method. All data were analyzed using the software packages R [71] and SPSS, version 12 [72].

\section{Results}

Sample characteristics of children and mothers are shown in tables 2 and 3. Mothers in the parent-child treatment rated the suitability of treatment (mean = $-1.14, \mathrm{SD}=1.21)$ similarly to participants in the parentexclusive treatment (mean $=-1.31, \mathrm{SD}=1.03$ ) after the first session, where treatment rationales were introduced $\left(t_{18}=0.32, p=0.75\right)$. In both treatment modalities, suitability ratings remained stable until post-treatment (parent-child CBT: mean $=-1.1, \mathrm{SD}=1.66$; specialized CBT for mothers only: mean $=-1.25, \mathrm{SD}=1.04, \mathrm{t}_{16}=0.22, \mathrm{p}=$ $0.83)$. At 6 -month follow-up, suitability ratings were maintained and again did not differ between groups (par- 
Table 3. Sample characteristics of mothers

\begin{tabular}{|c|c|c|c|c|c|}
\hline & \multicolumn{4}{|l|}{ Study groups } & \multirow{2}{*}{$\begin{array}{l}\text { Test statistic and } \\
\text { significance }\end{array}$} \\
\hline & mother-child CBT & & CBT for mothers only & & \\
\hline Sample size & 29 & & 25 & & \\
\hline Age (mean $\pm S D)$, years & $40.9 \pm 4.4$ & & $38.8 \pm 6.0$ & & $\mathrm{t}_{43}=1.47 ; \mathrm{p}=0.15$ \\
\hline $\mathrm{BMI}($ mean $\pm \mathrm{SD})$ & $29.6 \pm 7.5$ & $\mathrm{n}=21$ & $26.9 \pm 3.9$ & $\mathrm{n}=17$ & $\mathrm{t}_{31}=1.44 ; \mathrm{p}=0.16$ \\
\hline Mental disorders ${ }^{\mathrm{a}}$ & $8^{b}(29.6)$ & $\mathrm{n}=27$ & $6^{c}(25.0)$ & $\mathrm{n}=24$ & $\chi^{2}=0.14 ; p=0.71$ \\
\hline Low/medium/high SES category & $11 / 15 / 2(39.3 / 53.6 / 7.1)$ & $\mathrm{n}=28$ & $13 / 11 / 2(50.0 / 42.3 / 7.7)$ & $\mathrm{n}=26$ & $\chi^{2}=0.71 ; p=0.70$ \\
\hline
\end{tabular}

Figures in parentheses indicate percentages.

${ }^{a}$ Mini-DIPS [66]. ${ }^{b}$ Specific phobias $(n=3)$, major depression $(n=3)$, panic disorder $(n=1)$, social phobia $(n=1)$. ${ }^{c}$ Specific phobias $(n=3)$, social phobia $(n=1)$, generalized anxiety disorder $(n=1)$, posttraumatic stress disorder $(n=1)$.

ent-child CBT: mean $=-1.2, \mathrm{SD}=1.70$; specialized CBT for mothers only: mean $=-1.88, \mathrm{SD}=0.99, \mathrm{t}_{21}=1.20, \mathrm{p}=$ $0.68)$.

Nonspecific treatment indices ensured that quality and competences of therapists were equal in the two conditions. As mothers in the two treatment modalities received equal treatment, the treatment integrity ratings of parents revealed no differences between treatment-specific $\left(\mathrm{t}_{14}=-0.35, \mathrm{p}=0.73\right.$, gamma for interrater reliability $=0.62)$ and nonspecific $\left(\mathrm{t}_{14}=0.48, \mathrm{p}=0.64\right.$, gamma for interrater reliability $=0.29$ ) indices. Ratings of children's sessions indicated that the treatment-specific indices significantly differed between the treatments $\left(\mathrm{t}_{7}=\right.$ 9.86, $\mathrm{p}<0.001$ for the children's CBT-specific index, and $\mathrm{t}_{8}=-13.15, \mathrm{p}<0.001$ for the children's PMR-specific index), being higher for the CBT as expected, whereas the nonspecific contents were comparable in both treatments $\left(\mathrm{t}_{14}=1.58, \mathrm{p}=0.14\right)$. Interrater reliability was satisfactory with a gamma coefficient of $0.98(\mathrm{p}<0.001)$ for specific indices and $0.94(\mathrm{p}<0.001)$ for nonspecific indices.

Children in the parent-child CBT attended slightly more of the 10 sessions $(9.00, \mathrm{SD}=1.00)$ than those in the specialized CBT for mothers only $\left(7.75, \mathrm{SD}=2.01 ; \mathrm{t}_{13.7}=\right.$ $2.04, \mathrm{p}=0.06$ ). During follow-up, there was no difference in attendance of the 6 sessions between treatment conditions (mother-child CBT: $3.90, \mathrm{SD}=1.55,65.0 \%$; specialized CBT for mothers only: $4.0, \mathrm{SD}=1.16,66.6 \%$; $\mathrm{t}_{14.2}=$ $0.18, \mathrm{p}=0.88)$. The dropout rates between baseline and 6-month follow-up were $9(31.0 \%)$ and $17(70.8 \%)$ in the parent-child CBT and the specialized CBT for mothers only, respectively, and these proportions were significantly different from each other $\left(\chi^{2}=8.3, \mathrm{p}=0.004\right)$.

We further tested whether the probability of a family withdrawing from treatment was related to the following measures: sex, age, BMI, depression (BDI, DIKJ), anxiety (BAI, STAIK-T), comorbid mental disorders of children and mothers, or EDE global score of mothers using $t$ tests (for continuously distributed variables) or Fisher's exact tests $/ \chi^{2}$ tests (for categorical variables). None of the comparisons between withdrawers and completers reached statistical significance for any of these variables ( $p>0.05$ for all comparisons) except that younger mothers were more likely to be missing at 6-month follow-up than older mothers $(\mathrm{p}=0.008)$.

\section{Primary Outcomes}

Children in both treatment modalities reduced their percent overweight between baseline and 6-month follow-up ( $\mathrm{p}<0.001$ for linear trend). This reduction was faster early in the treatment phase and slower thereafter ( $p=0.002$ for quadratic trend). The temporal courses of the two treatments, however, did not differ $(p=0.43$ for interaction linear trend $\times$ treatment, $p=0.83$ for interaction quadratic trend $\times$ treatment; fig. 2). Estimated means from the linear mixed model are shown in table 4 . Effect sizes (Cohen's d) for percent overweight between the two treatments were 0.32 and 0.29 at the end of treatment and at 6-month follow-up, respectively.

There were no changes in mothers' BMI between baseline and 6-month follow-up ( $p=0.76$ for linear time trend, $p=0.85$ for quadratic trend) and the temporal course was not influenced by treatment modalities $(\mathrm{p}=$ 0.77 for interaction linear trend $\times$ treatment, $p=0.48$ for interaction quadratic trend $\times$ treatment, see also table 5). Effect sizes for mothers' BMI between the two treatments were 0.37 and 0.44 at the end of treatment and at 6-month follow-up, respectively. 
Fig. 2. Course of children's percent overweight (values denote estimated marginal means from a linear mixed model).

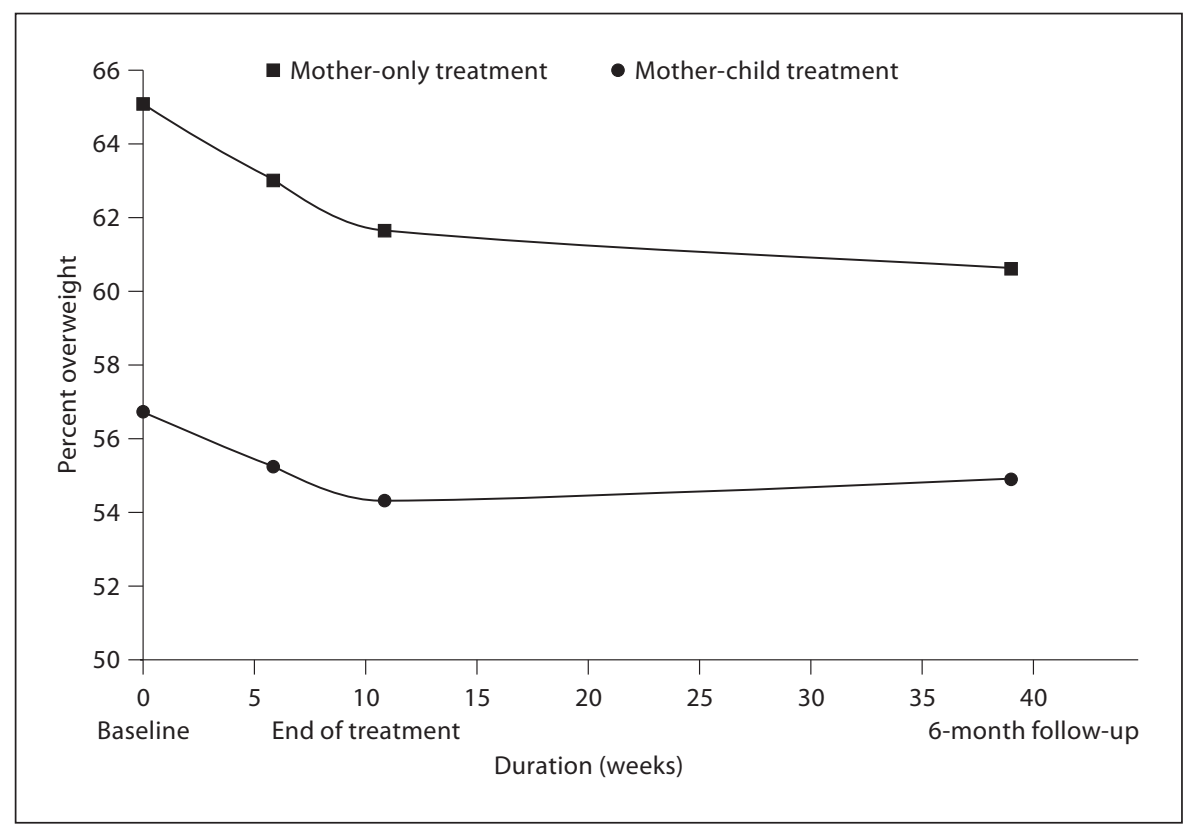

Table 4. Primary and secondary outcomes of children at baseline, end of treatment, and end of follow-up

\begin{tabular}{|c|c|c|c|c|c|c|c|c|c|c|c|c|}
\hline \multirow[t]{3}{*}{ Variable } & \multicolumn{4}{|l|}{ Baseline } & \multicolumn{4}{|c|}{ End of treatment } & \multicolumn{4}{|c|}{ End of follow-up } \\
\hline & \multirow{2}{*}{$\begin{array}{l}\begin{array}{l}\text { mother- } \\
\text { child CBT }\end{array} \\
\text { mean }\end{array}$} & \multicolumn{3}{|c|}{$\begin{array}{l}\text { CBT for } \\
\text { mothers only }\end{array}$} & \multirow{2}{*}{$\begin{array}{l}\begin{array}{l}\text { mother- } \\
\text { child CBT }\end{array} \\
\text { mean }\end{array}$} & \multicolumn{3}{|c|}{$\begin{array}{l}\text { CBT for } \\
\text { mothers only }\end{array}$} & \multirow{2}{*}{$\begin{array}{l}\begin{array}{l}\text { mother- } \\
\text { child CBT }\end{array} \\
\text { mean }\end{array}$} & \multicolumn{3}{|c|}{$\begin{array}{l}\text { CBT for } \\
\text { mothers only }\end{array}$} \\
\hline & & mean & SE & $\mathrm{p}$ & & mean & SE & $\mathrm{p}$ & & mean & SE & $\mathrm{p}$ \\
\hline Percent overweight & 56.76 & 65.09 & 6.12 & 0.18 & 54.29 & 61.59 & 6.46 & 0.26 & 54.85 & 60.57 & 7.64 & 0.46 \\
\hline DIKJ total score & 2.32 & 2.48 & 0.31 & 0.60 & 1.23 & 1.88 & 0.45 & 0.16 & 1.66 & 1.79 & 0.54 & 0.82 \\
\hline STAIK-T total score & 3.37 & 3.33 & 0.06 & 0.52 & 3.14 & 3.18 & 0.07 & 0.58 & 3.19 & 3.25 & 0.09 & 0.47 \\
\hline SASC-R SAD & 4.26 & 3.98 & 0.17 & 0.10 & 3.72 & 3.61 & 0.19 & 0.57 & 3.65 & 3.56 & 0.24 & 0.69 \\
\hline SASC-R FNE & 2.89 & 2.91 & 0.11 & 0.78 & 2.62 & 2.57 & 0.13 & 0.72 & 2.49 & 2.86 & 0.16 & 0.03 \\
\hline CBCL global score & 4.51 & 5.31 & 0.54 & 0.14 & 3.78 & 4.18 & 0.59 & 0.51 & 4.27 & 4.63 & 0.73 & 0.64 \\
\hline
\end{tabular}

Means denote estimates from a linear mixed model. Standard errors of differences between the two group means (SE) are shown, including error probability (p), which allows testing for significant differences between the two treatment values at the given time points, based on a t test for independent samples.

\section{Secondary Outcomes}

For the secondary outcomes in children, we found significant linear decreases between baseline and 6-month follow-up for depressive feelings and for all anxiety measures $(p<0.001$ for linear trend in variables SAD, DIKJ, FNE, STAIK, and CBCL total score). In all these cases, a quadratic polynomial significantly improved the model fit ( $\mathrm{p} \leq 0.005$ for linear and quadratic trends in all five variables). Thus, the trends observed for these variables during the treatment phase were either decelerated (SAD) or slightly reversed (DIKJ, FNE, STAIK, and CBCL total score) toward the 6-month follow-up (table 4). The temporal course did not vary across the two treatments $(\mathrm{p}>$ 0.1 for all secondary outcomes and for both interactions, linear trend $\times$ treatment and quadratic trend $\times$ treatment). Estimated means based on the linear mixed model showed that only the FNE at 6-month follow-up differed between the two treatments with lower values for the mother-child treatment compared to the specialized CBT for the mothers (table 4). 
Table 5. Primary and secondary outcomes of mothers at baseline, end of treatment, and end of follow-up

\begin{tabular}{|c|c|c|c|c|c|c|c|c|c|c|c|c|}
\hline \multirow[t]{3}{*}{ Variable } & \multicolumn{4}{|l|}{ Baseline } & \multicolumn{4}{|c|}{ End of treatment } & \multicolumn{4}{|c|}{ End of follow-up } \\
\hline & \multirow{2}{*}{$\begin{array}{l}\begin{array}{l}\text { mother- } \\
\text { child CBT }\end{array} \\
\text { mean }\end{array}$} & \multicolumn{3}{|c|}{$\begin{array}{l}\text { CBT for } \\
\text { mothers only }\end{array}$} & \multirow{2}{*}{$\begin{array}{l}\begin{array}{l}\text { mother- } \\
\text { child CBT }\end{array} \\
\text { mean }\end{array}$} & \multicolumn{3}{|c|}{$\begin{array}{l}\text { CBT for } \\
\text { mothers only }\end{array}$} & \multirow{2}{*}{$\begin{array}{l}\begin{array}{l}\text { mother- } \\
\text { child CBT }\end{array} \\
\text { mean }\end{array}$} & \multicolumn{3}{|c|}{$\begin{array}{l}\text { CBT for } \\
\text { mothers only }\end{array}$} \\
\hline & & mean & SE & $\mathrm{p}$ & & mean & SE & $\mathrm{p}$ & & mean & SE & $\mathrm{p}$ \\
\hline BMI & 29.64 & 27.34 & 1.69 & 0.17 & 29.60 & 27.40 & 1.69 & 0.19 & 29.70 & 27.21 & 1.70 & 0.15 \\
\hline BDI & 1.95 & 2.10 & 0.31 & 0.64 & 1.61 & 1.01 & 0.42 & 0.16 & 1.57 & 1.15 & 0.55 & 0.47 \\
\hline BAI & 1.20 & 1.52 & 0.29 & 0.28 & 1.04 & 1.05 & 0.29 & 0.97 & 1.07 & 0.68 & 0.40 & 0.36 \\
\hline
\end{tabular}

Means denote estimates from a linear mixed model. Standard errors of differences between the two group means (SE) are shown, including error probability (p), which allows testing for significant differences between the two treatment values at the given time points, based on a test for independent samples.

Mothers' secondary outcomes revealed a significant interaction between time and treatment modality for the BDI. Whereas in the mother-child CBT results for the BDI only moderately decreased throughout the study, in the specialized CBT for the mother only, these values strongly decreased, especially early in the treatment phase ( $\mathrm{p}=0.033$ for interaction quadratic trend $\times$ treatment). Results for the BAI were similar but less pronounced than for the BDI. BAI values in the CBT for mothers only tended to decrease until the 6-month follow-up ( $\mathrm{p}=0.097$ for interaction linear trend $\times$ treatment). Estimated means are shown in table 5.

\section{Discussion}

The main goal of our study was to compare the efficacy of a specialized CBT for parents only to a specialized parent-child treatment with respect to the reduction of children's percent overweight and psychological parameters. Our study results show that both treatments were efficacious with respect to the reduction of overweight in children between baseline and 6-month follow-up and that these reductions were similar between the two treatments. During treatment, anxious and depressive feelings in both children and mothers and overall behavior problems in children were significantly improved and maintained until follow-up. As depressive symptoms might be a valuable predictor for adolescent and adult obesity [73], future studies should investigate whether a lasting improvement in psychological parameters is associated with better long-term maintenance of weight reduction.

The overweight reduction in our study was less pronounced than in comparable treatment studies $[10,27,28$,
$31-33,74,75]$. However, it should be kept in mind that our results are based on linear mixed models whereas other authors often performed completer analyses [31, 32, 75], which can lead to biased results [70]. For example in our study, percent overweight between baseline and 6-month follow-up was reduced by 1.9 (mother-child CBT) and 4.5 (mother-only CBT) percentage points based on a linear mixed model. Corresponding values are -1.0 (motherchild CBT) and -7.1 (mother-only CBT) percentage points based on a completer analysis using a split-plot repeatedmeasures design and -1.9 (mother-child CBT) and -2.8 (mother-only CBT) percentage points based on an intentto-treat analysis (LOCF method). Other explanations for the smaller weight reduction rate in our sample might be the lower frequency of sessions [11,31,32, 75-77] or the high rates of comorbid mental disorders that might have influenced treatment outcome negatively.

Several concerns have to be addressed when discussing our results. As our randomization procedure resulted in an unequal number of groups of each treatment modality we could not control for seasonal effects on weight course for one group [78, 79]. We further had to exclude fathers from our analyses; hence we can only draw conclusions about the role of the mothers in treatment of obese children. Another limitation concerns the lack of information about physical activity or eating behavior of the children during the study course, although these were major topics of the treatment. Further, the follow-up period of 6 months does not satisfy the criteria of evaluating long-term efficacy as obese individuals are known to compensate for their weight loss [80]. The major limitations of this study are the small sample size and the high dropout rates, which exceed those for parent-exclusive treatments mentioned in the literature [81]. Although we undertook intensive efforts to recruit families over a 
2-year period, we did not succeed in reaching a sample size that would allow us to detect a moderate effect size. During the recruitment we often encountered the phenomenon of parents not recognizing their child's health risk from being overweight or obese [82-84]. Moore et al. [85] suggested, and we agree, that training of the research staff should be incorporated into the study design, to enhance the quality of the recruitment efforts. Judging by our clinical experience, one reason for the overall high dropout rates may be that many mothers, busy with family life and career, were overwhelmed by the effort needed to sustain long-term lifestyle changes and weight stabilization in their children. By the end of follow-up, considerably more families had withdrawn from the specialized CBT for mothers only than from the mother-child treatment. There are two possible explanations for this finding. First, the PMR condition might have disappointed and discouraged the children [86]. Second, the lack of ad- herence in this group might reflect difficulties mothers had in taking over the sole responsibility for initiating and maintaining behavior change. We conclude that there is a need for future research to enhance mothers' motivation to foster long-term behavior change in obese children.

\section{Acknowledgement}

The treatment trial was funded by the Swiss National Science Foundation (SNF; 3251-067078.01), which supports research projects of general interest to the Swiss public. The SNF approved the initial study design and is informed yearly about the progress of the ongoing study but does not intervene with the scientific content or results. Publication of the results is done independently of the SNF. The principal investigator (S.M.) had full access to all the data in the study and takes responsibility for the integrity of the data and the accuracy of the data analysis.

\section{References}

1 Ogden CL, Flegal KM, Carroll MD, Johnson CL: Prevalence and trends in overweight among us children and adolescents, 19992000. JAMA 2002;288:1728-1732.

2 Livingstone MB: Childhood obesity in Europe: a growing concern. Public Health Nutr 2001;4:109-116.

3 Rolland-Cachera MF, Castetbon K, Arnault N, Bellisle F, Romano MC, Lehingue Y, Frelut ML, Hercberg S: Body mass index in 7-9$\mathrm{y}$-old French children: frequency of obesity, overweight and thinness. Int J Obes Relat Metab Disord 2002;26:1610-1616.

-4 Lobstein TJ, James WP, Cole TJ: Increasing levels of excess weight among children in England. Int J Obes Relat Metab Disord 2003;27:1136-1138.

5 Zimmermann MB, Gubeli C, Puntener C, Molinari L: Detection of overweight and obesity in a national sample of 6-12-y-old Swiss children: accuracy and validity of reference values for body mass index from the US Centers for Disease Control and Prevention and the International Obesity Task Force. Am J Clin Nutr 2004;79:838-843.

-6 Sinha R, Fisch G, Teague B, Tamborlane WV, Banyas B, Allen K, Savoye M, Rieger V, Taksali S, Barbetta G, Sherwin RS, Caprio S: Prevalence of impaired glucose tolerance among children and adolescents with marked obesity. N Engl J Med 2002;346:802-810.

7 Lumeng JC, Gannon K, Cabral HJ, Frank DA, Zuckerman B: Association between clinically meaningful behavior problems and overweight in children. Pediatrics 2003; 112:1138-1145.
8 Mustillo S, Worthman C, Erkanli A, Keeler G, Angold A, Costello EJ: Obesity and psychiatric disorder: developmental trajectories. Pediatrics 2003;111:851-859.

-9 Zeller M, Daniels S: The obesity epidemic: family matters. J Pediatr 2004;145:3-4.

10 Epstein LH, McKenzie SJ, Valoski A, Klein KR, Wing RR: Effects of mastery criteria and contingent reinforcement for family-based child weight control. Addict Behav 1994;19: 135-145.

11 Marcus MD, Kalarchian MA: Binge eating in children and adolescents. Int J Eat Disord 2003;34(suppl):S47-S57.

12 Holtkamp K, Konrad K, Muller B, Heussen N, Herpertz S, Herpertz-Dahlmann B, Hebebrand J: Overweight and obesity in children with attention-deficit/hyperactivity disorder. Int J Obes Relat Metab Disord 2004;28:685-689.

13 Agranat-Meged AN, Deitcher C, Goldzweig G, Leibenson L, Stein M, Galili-Weisstub E: Childhood obesity and attention deficit/hyperactivity disorder: A newly described comorbidity in obese hospitalized children. Int J Eat Disord 2005;37:357-359.

14 Epstein LH, Klein KR, Wisniewski L: Child and parent factors that influence psychological problems in obese children. Int J Eat Disord 1994;15:151-158.

15 Buddeberg-Fischer B, Klaghofer R, Reed V: Associations between body weight, psychiatric disorders and body image in female adolescents. Psychother Psychosom 1999;68: 325-332.
6 Pudel V, Ellrott T: Nutrition behavior in Germany. Internist (Berl) 1995;36:1032-1039.

17 Westerterp KR: Food quotient, respiratory quotient, and energy balance. Am J Clin Nutr 1993;57:759S-765S.

18 Gortmaker SL, Must A, Perrin JM, Sobol AM, Dietz WH: Social and economic consequences of overweight in adolescence and young adulthood. N Engl J Med 1993;329: 1008-1012.

19 Davies PS, Gregory J, White A: Physical activity and body fatness in pre-school children. Int J Obes Relat Metab Disord 1995;19: 6-10.

20 Laessle RG, Uhl H, Lindel B, Muller A: Parental influences on laboratory eating behavior in obese and non-obese children. Int J Obes Relat Metab Disord 2001;25(suppl 1): S60-S62.

21 Birch LL, Fisher JO: Development of eating behaviors among children and adolescents. Pediatrics 1998; 101:539-549.

-22 Fogelholm M, Nuutinen O, Pasanen M, Myohanen E, Saatela T: Parent-child relationship of physical activity patterns and obesity. Int J Obes Relat Metab Disord 1999; 23:1262-1268.

23 Epstein LH, Paluch RA, Gordy CC, Dorn J: Decreasing sedentary behaviors in treating pediatric obesity. Arch Pediatr Adolesc Med 2000;154:220-226.

24 Kohl HW 3rd, Hobbs KE: Development of physical activity behaviors among children and adolescents. Pediatrics 1998;101:549554. 
25 Kirschenbaum DS, Harris ES, Tomarken AJ: Effects of parental involvement in behavioral weight loss therapy for preadolescents. Behav Ther 1984;15:485-500.

-26 Epstein LH, Valoski A, Wing RR, McCurley $\mathrm{J}$ : Ten-year outcomes of behavioral familybased treatment for childhood obesity. Health Psychol 1994;13:373-383.

-27 Coates TJ, Killen JD, Slinkard LA: Parent participation in a treatment program for overweight adolescents. Int J Eat Disord 1982;1:37-48.

28 Brownell KD, Kelman JH, Stunkard AJ: Treatment of obese children with and without their mothers: changes in weight and blood pressure. Pediatrics 1983;71:515-523.

29 Israel AC, Stolmaker L, Andrian CA: The effects of training parents in general child management skills on a behavioral weight loss program for children. Behav Ther 1985; 16:169-180.

30 Flodmark CE, Ohlsson T, Ryden O, Sveger T: Prevention of progression to severe obesity in a group of obese schoolchildren treated with family therapy. Pediatrics 1993;91:880884.

31 Golan M, Fainaru M, Weizman A: Role of behaviour modification in the treatment of childhood obesity with the parents as the exclusive agents of change. Int J Obes Relat Metab Disord 1998;22:1217-1224.

32 Golan M, Crow S: Parents are key players in the prevention and treatment of weight-related problems. Nutr Rev 2004;62:39-50.

33 Golan M, Kaufman V, Shahar DR: Childhood obesity treatment: targeting parents exclusively v parents and children. Br J Nutr 2006;95:1008-1015.

34 Harper LV, Sanders KM: The effects of adults' eating on young children's acceptance of unfamiliar foods. J Exp Child Psychol 1975;20:206-214.

- 35 Epstein LH, Masek BJ, Marshall WR: A nutritionally based school program for control of eating in obese children. Behav Ther 1978; 9:766-778.

-36 Epstein LH, Woodall K, Goreczny AJ, Wing RR, Robertson RJ: The modification of activity patterns and energy expenditure in obese young girls. Behav Ther 1984;15:101-108.

37 American Psychiatric Association: Diagnostic and Statistical Manual of Mental Disorders, ed 4, revised. Washington, American Psychiatric Association, 2000.

38 Buchner A, Erdfelder E, Faul F: How to use G*Power. http://www.psycho.uni-duesseldorf.de/aap/projects/gpower/how_to_use gpower.html. 1997.

39 Kracht M: Randomisierung; in Adam J (ed): Statistisches Know-how in der medizinischen Forschung. Berlin, Ullstein Mosby $\mathrm{GmbH}, 1992$, pp 172-210.
40 Wilfley DE, Welch RR, Stein RI, Spurrell EB, Cohen LR, Saelens BE, Dounchis JZ, Frank MA, Wiseman CV, Matt GE: A randomized comparison of group cognitive-behavioral therapy and group interpersonal psychotherapy for the treatment of overweight individuals with binge-eating disorder. Arch Gen Psychiatry 2002;59:713-721.

41 Ilardi SS, Craighead WE: The relationship between personality pathology and dysfunctional cognitions in previously depressed adults. J Abnorm Psychol 1999;108:51-57.

42 Howard KI, Kopta SM, Krause MS, Orlinsky DE: The dose-effect relationship in psychotherapy. Am Psychol 1986;41:159-164.

43 Senediak C, Spence SH: Rapid versus gradual scheduling of therapeutic contact in a family based behavioural weight control programme for children. Behav Psychother 1985;13:265-287.

44 Barlow SE, Dietz WH: Obesity evaluation and treatment: expert committee recommendations. The maternal and child health bureau, health resources and services administration and the department of health and human services. Pediatrics 1998;102: E29.

45 Summerbell CD, Ashton V, Campbell KJ Edmunds L, Kelly S, Waters E: Interventions for treating obesity in children. Cochrane Database Syst Rev 2003;3:CD001872.

46 Fiedler P: Verhaltenstherapie in und $\mathrm{mit}$ Gruppen. Weinheim, Beltz, Psychologie Verlags Union, 1996.

47 Epstein LH, Squires S: The Stoplight Diet for Children: An Eight-Week Program for Parents and Children. Boston, Little Brown \& Co, 1988.

48 Epstein LH: Application of behavioral economic principles to treatment of childhood obesity; in Allison DB, Pi-Sunyer XF (eds): Obesity Treatment: Establishing Goals, Improving Outcomes and Reviewing the Research Agenda. New York, Plenum Press, 1995.

49 Speck V: Training progressiver Muskelentspannung für Kinder. Göttingen, Hogrefe, 2005.

50 Stiensmeier-Pelster J, Schürmann M, Duda $\mathrm{K}$ : Depressionsinventar für Kinder und Jugendliche. Bern, Huber, 2000.

51 Spielberger CD: Manual for the State Trait Anxiety Inventory for Children (STAI-C). Palo Alto Consulting Psychologist Press, 1973.

52 Laux L, Glanzmann P, Schaffner P, Spielberger CD: Das State-Trait-Angstinventar. Weinheim, Beltz, 1981.

53 La Greca AM, Stone WL: Social anxiety scale for children - revised: factor structure and concurrent validity. J Clin Child Psychol 1993;22:17-27.

54 Melfsen S, Florin I: Ein Fragebogen zur Erfassung sozialer Angst bei Kindern (SASCR-D). Kindheit Entwicklung 1997;6:224229.
55 Achenbach TM: Manual for the Child Behavior Checklist/4-18 and 1991 Profile. Burlington, University of Vermont Department of Psychiatry, 1991.

56 Melchers P, Döpfner M: Deutsche Bearbeitung des Elternfragebogens. Köln, Arbeitsgruppe Kinder-, Jugend- und Familiendiagnostik, 1993.

57 Fairburn CG, Cooper PJ: The eating disorder examination; in Fairburn CG, Wilson GT (eds): Binge Eating: Nature, Assessment, and Treatment. New York, Guilford Press, 1993, pp 317-360.

58 Hilbert A, Tuschen Caffier B, Ohms M: Eating disorders examination: a German version of the structured eating disorder interviews. Diagnostica 2004;50:98-106.

59 Beck AT, Ward CH, Mendelson M, Mock J, Erbaugh J: An inventory for measuring depression. Arch Gen Psychiatry 1961;4:561571.

60 Hautzinger M, Bailer M, Worall H, Keller F: Beck-Depressions-Inventar. Bern, Huber, 1995.

61 Beck AT, Epstein N, Brown G, Steer RA: An inventory for measuring clinical anxiety: psychometric properties. J Consult Clin Psychol 1988;56:893-897.

62 Margraf J, Ehlers A: Beck Angstinventar, deutsche Version. Bern, Huber, in press.

63 Brähler E, Fahrenberg J, Myrtek M, Schumacher J: Fragebogen zur Erfassung der Lebenszufriedenheit. Bern, Huber, 1998.

64 Kromeyer-Hauschild K, Wabitsch M, Kunze D, Geller F, Geiss HC, Hesse V, von Hippel A, Jaeger U, Johnson C, Korte W, Menner K, Müller G, Müller JM, Niemann-Pilatus A, Remer T, Schaefer F, Wittchen H-U, Zabransky S, Zellner K, Ziegler A, Hebebrand J: Perzentile für den Body-Mass-Index für das Kinderund Jugendalter unter Heranziehung verschiedener deutscher Stichproben. Monatsschr Kinderheilkd 2001;149:807-818.

65 Schneider S, Unnewehr S, Margraf J: KinderDIPS. Diagnostisches Interview bei psychischen Störungen im Kindes- und Jugendalter. Handbuch. Berlin, Springer, 1998.

66 Margraf J: Mini-DIPS. Berlin, Springer, 1994.

67 Kovacs M: Children's Depression Inventory. New York, MHS Inc, 1992

68 Grawe K, Siegfried J, Bernauer F, Donat R: Quality analysis of psychotherapy research: an empirical study. Schweiz Z Psychol Anwend 1987;46:259-266.

69 Little RJA, Rubin DB: Statistical Analysis with Missing Data, ed 2. Hoboken, Wiley, 2002.

70 Molenberghs G, Verbeke G: Meaningful statistical model formulations for repeated measures. Stat Sin 2004;14:989-1020. 
71 R Development Core Team: R: A Language and Environment for Statistical Computing. Vienna, R Foundation for Statistical Computing, 2006. http://www.R-project.org.

72 SPSS for Windows, rel 14.0. Chicago, SPSS Inc, 2001.

-73 Hasler G, Pine DS, Kleinbaum DG, Gamma A, Luckenbaugh D, Ajdacic V, Eich D, Rossler W, Angst J: Depressive symptoms during childhood and adult obesity: the Zurich cohort study. Mol Psychiatry 2005; 10:842850.

-74 Israel AC, Guile CA, Baker JE, Silverman WK: An evaluation of enhanced self-regulation training in the treatment of childhood obesity. J Pediatr Psychol 1994;19:737-749.

-75 Epstein LH, Valoski AM, Vara LS, McCurley J, Wisniewski L, Kalarchian MA, Klein KR, Shrager LR: Effects of decreasing sedentary behavior and increasing activity on weight change in obese children. Health Psychol 1995; 14:109-115.

-76 Epstein LH, Paluch RA, Gordy CC, Saelens BE, Ernst MM: Problem solving in the treatment of childhood obesity. J Consult Clin Psychol 2000;68:717-721.
77 Epstein LH, Paluch RA, Raynor HA: Sex differences in obese children and siblings in family-based obesity treatment. Obes Res 2001;9:746-753.

78 Andersson I, Rossner S: The Christmas factor in obesity therapy. Int J Obes Relat Metab Disord 1992;16:1013-1015.

79 Gillis L, McDowell M, Bar-Or O: Relationship between summer vacation weight gain and lack of success in a pediatric weight control program. Eat Behav 2005;6:137-143.

80 Beutel ME, Dippel A, Szczepanski M, Thiede R, Wiltink J: Mid-term effectiveness of behavioral and psychodynamic inpatient treatments of severe obesity based on a randomized study. Psychother Psychosom 2006;75: 337-345.

81 Whitlock EP, Williams SB, Gold R, Smith PR, Shipman SA: Screening and interventions for childhood overweight: a summary of evidence for the US Preventive Services Task Force. Pediatrics 2005;116:e125-e144.
82 Jeffery AN, Voss LD, Metcalf BS, Alba S, Wilkin TJ: Parent's awareness of overweight in themselves and their children; cross sectional study within a cohort (EarlyBird 21). BMJ 2005;330:23-24.

83 Etelson D, Brand DA, Patrick PA, Shirali A: Childhood obesity: do parents recognize this health risk? Obes Res 2003;11:13621368

84 Rhee KE, De Lago CW, Arscott-Mills T, Mehta SD, Davis RK: Factors associated with parental readiness to make changes for overweight children. Pediatrics 2005;116:e94e101.

85 Moore H, Summerbell C, Vail A, Greenwood DC, Adamson AJ: The design features and practicalities of conducting a pragmatic cluster randomized trial of obesity management in primary care. Stat Med 2001;20:331340.

86 Duffy G, Spence SH: The effectiveness of cognitive self-management as an adjunct to a behavioural intervention for childhood obesity: a research note. J Child Psychol Psychiatry 1993;34:1043-1050. 